\title{
Long COVID in general practice: an analysis of the equity of NHS England's enhanced service specification
}

DOI:

https://doi.org/10.3399/bjgp22X718505

\section{Document Version}

Final published version

Link to publication record in Manchester Research Explorer

\section{Citation for published version (APA):}

Hutchinson, J., Checkland, K., Munford, L., Khavandi, S., \& Sutton, M. (2022). Long COVID in general practice: an analysis of the equity of NHS England's enhanced service specification. British Journal of General Practice, 72(715), 85-86. https://doi.org/10.3399/bjgp22X718505

\section{Published in:}

British Journal of General Practice

\section{Citing this paper}

Please note that where the full-text provided on Manchester Research Explorer is the Author Accepted Manuscript or Proof version this may differ from the final Published version. If citing, it is advised that you check and use the publisher's definitive version.

\section{General rights}

Copyright and moral rights for the publications made accessible in the Research Explorer are retained by the authors and/or other copyright owners and it is a condition of accessing publications that users recognise and abide by the legal requirements associated with these rights.

\section{Takedown policy}

If you believe that this document breaches copyright please refer to the University of Manchester's Takedown Procedures [http://man.ac.uk/04Y6Bo] or contact uml.scholarlycommunications@manchester.ac.uk providing relevant details, so we can investigate your claim.

\section{OPEN ACCESS}




\title{
Analysis
}

\section{Long COVID in general practice:}

\author{
an analysis of the equity of NHS England's enhanced service specification
}

\section{INTRODUCTION}

On 5 September 2021, $1.7 \%$ of the UK population reported suffering from prolonged symptoms 4 weeks after COVID19 infection, the syndrome becoming known as long COVID, ${ }^{1}$ most commonly causing fatigue, headaches, and attention difficulties. ${ }^{2}$

Despite the vaccination programme, in the autumn of 2021 approximately 40000 COVID-19 cases were still being recorded daily, of which an estimated 3.0-11.7\% will subsequently develop long COVID. ${ }^{3,4}$ Therefore, long COVID will continue to be a problem into the future.

Deprived populations have a greater prevalence of diseases, which render them at greater risk of serious illness with COVID19 , as well as social factors that increase viral exposure such as dense housing or occupational exposure. ${ }^{5}$ Meanwhile, the inverse care law means these populations have more limited access to healthcare services, demonstrated in part by the lower numbers of GPs per patient in deprived populations, ${ }^{6,7}$

General practice is the first point of contact of the NHS for these patients. Therefore, the commissioning and funding of services in general practice for patients with long COVID needs to take account of these factors to prevent a continuation or exacerbation of the disproportionate COVID-19 impact on deprived populations.

\section{SERVICE SPECIFICATION}

NHS England (NHSE) has established an enhanced service contract intended to support general practice workforce planning, training needs, and infrastructure to address long COVID. ${ }^{8}$ The service specification details an assessment pathway, with GPs required to assess patients and consider onward referral. This will result in additional clinical work that needs to be accommodated within existing workloads, potentially increasing the pressure on general practices. While care of patients with long COVID does fall under the requirements of the General Medical Services contract, this novel disease represents a significant potential workload burden for general practices. The enhanced service payment, although intended largely to support education and coding activity, provides the only mechanism by which practices are being compensated for the extra work.
NHSE's long COVID plan reflects the need to narrow health inequalities resulting from the pandemic. Theenhanced service requires practices to consider how to reduce inequity of access within their practice population with regard to long COVID. However, this does not address inter-practice inequity and the funding mechanism does not account for deprivation or geographical difference, thereby potentially exacerbating the inequity between communities.

\section{FUNDING MECHANISM}

The enhanced service is funded through a capitation payment, whereby the practice receives $€ 0.371$ per registered patient topped up to $€ 0.495$ per patient upon selfassessment of completion.

The payments are not weighted for any factors that reflect need for long COVID services or affect the costs of delivering these services. Most obviously, this flat-rate funding mechanism contains no adjustment for prevalence; therefore, populations with high prevalence will receive proportionally less funding per long COVID patient than those with lower prevalence.

\section{LONG COVID DISTRIBUTION}

It was estimated that 945000 people had long COVID in England as of 5 September 2021.' Assuming 100\% uptake of this enhanced service by general practices across England, approximately £28 million will be claimed in 2021/2022, equating to €29.62 for each long COVID case.

This £29.62 figure reflects COVID-19 cases occurring prior to 8 August 2021, given the 4-week delay before developing long COVID. If 5.3 million people had COVID-19 by 8 August 2021,3 this suggests a conversion rate of COVID-19 to long COVID of $17.68 \%$, higher than the Office for National Statistics conversion estimates, which likely reflects higher incidence if self-reported. ${ }^{4}$

There is very substantial variation in rates of long COVID across England. Using cumulative case rates, the Upper-Tier Local Authorities of Blackburn and Darwen had an estimated long COVID case rate of 3047 per 100000 people while Dorset had 831 by 5 September 2021. This results in Blackburn and Darwen receiving £16.25 per long COVID case while Dorset will receive E59.53. A practice with 9000 patients will receive $€ 4455$ under the enhanced service; in Blackburn and Darwen they will have an estimated 274 patients with long COVID while in Dorset they would have only 75.

COVID-19 incidence since September has remained high, which will result in cumulative incidence of long COVID increasing. As this funding is fixed, funding per case will steadily decrease. For example, the $€ 4455$ in Blackburn and Darwen for 274 patients in September will need to be used for an estimated 327 patients by December.

\section{PREVALENCE DISTRIBUTION}

The geographic maldistribution of COVID19 is caused by a number of different factors, such as socioeconomics.

\section{Socioeconomic inequalities}

COVID-19 has had a disproportionate impact on deprived populations. ${ }^{5}$ Table 1 details how funding per case of long COVID varies by quintile of population deprivation. The most deprived areas receive £13.01 less per case than the least.

\section{Regional inequalities}

The North of England has also been disproportionately affected by COVID-19.? Table 2 shows this in funding per long COVID case, for example, the North-East receives $54 \%$ of the funding of the South-East.

\section{THE IMPACT OF THE CURRENT FUNDING MODEL}

The flat-rate funding model chosen for the long COVID enhanced service risks exacerbating the problems experienced during the pandemic. COVID-19 has had a disproportionate impact on the North and deprived areas, with an increased disease

\section{Table 1. Long COVID funding per case by deprivation quintiles - 5 September 2021 (self-reported long COVID of any duration)}

\begin{tabular}{lll} 
Deprivation & $\begin{array}{l}\text { Estimated } \\
\text { population } \\
\text { with long } \\
\text { quintile }\end{array}$ & $\begin{array}{l}\text { Funding per } \\
\text { COVID, } \%\end{array}$ \\
\hline 1 (Most deprived) & 2.09 & 23.81 \\
\hline 2 & 1.92 & 25.92 \\
\hline 3 & 1.72 & 28.93 \\
\hline 4 & 1.45 & 34.32 \\
\hline 5 (Least deprived) & 1.35 & 36.82 \\
\hline England & 1.68 & 29.62 \\
\hline
\end{tabular}




\section{Table 2. Long COVID funding per case by region of England -5 September 2021 (self- reported long COVID of any duration)}

\begin{tabular}{lll} 
& $\begin{array}{l}\text { Estimated } \\
\text { population with } \\
\text { long COVID, \% }\end{array}$ & $\begin{array}{l}\text { Funding per } \\
\text { case, } \mathbf{E}\end{array}$ \\
\hline Region & 2.69 & 18.50 \\
\hline North-East & 24.28 \\
\hline North-West & 2.05 & 25.39 \\
\hline East Midlands & 1.96 & 27.05 \\
\hline West Midlands & 1.84 & 28.77 \\
\hline Yorkshire and & 1.73 & \\
the Humber & & 31.10 \\
\hline South-West & 1.60 & 31.70 \\
\hline London & 1.57 & 34.08 \\
\hline East of & 1.46 & 34.31 \\
England & & 29.62 \\
\hline South-East & 1.45 & \\
\hline England & 1.68 &
\end{tabular}

and mortality burden. ${ }^{5,9}$ This has resulted in these communities taking greater economic damage, such as a greater increase in unemployment. ${ }^{10}$ This in turn leads to slower economic recovery in these communities, already evident in a slower consumer spending recovery. ${ }^{10}$ Unfortunately, strategies to control COVID-19 may also be showing signs of inequity, with vaccine hesitancy greater in deprived populations. ${ }^{11}$

To mitigate these effects it is necessary to provide differential support for populations that have experienced the greatest impact during the pandemic, including this enhanced service for long COVID.

\section{ALTERNATIVES}

There are a variety of ways to reimburse GPS. One option is to use a fee-for-service, with a fixed payment per long COVID assessment. Alternatively, payments could be linked to outcomes rather than activities, which in this case may be the number of cases identified. ${ }^{12}$ However, this may incentivise overdiagnosis and overprovision. ${ }^{12}$

The majority of funding for general practice in England is on a weighted capitation basis. Carr-Hill formula weights practice payments according to differences in workload secondary to practice population factors, such as deprivation. The long COVID enhanced service funding could be weighted, which would partly address the difference in case rates between deprived populations. It would also provide more funding for older practice populations, who are more likely to develop long COVID. ${ }^{4}$ However, only part of the variation in the Carr-Hill formula is explained by deprivation and age, with other adjustments for list turnover and input prices. Further, the Carr-Hill formula may worsen funding inequity in less deprived practices with high case rates.

Alternatively, funding could be weighted according to case rate in the corresponding local authority, which may more accurately reflect long COVID workload. This may enable the disproportionate healthcare burden to be alleviated in the worst affected areas

\section{CONCLUSION}

COVID-19 has disproportionately impacted deprived populations. Therefore, it is important that we support these communities to recover to prevent worsening inequity. The government has expressed a desire to address longstanding inequalities that have been highlighted by the pandemic. Unfortunately, the funding formula used for the long COVID enhanced service fails to reflect this and will act instead to create a new inequity. This may further compound the existing effect from the pandemic.

\section{Joseph Hutchinson,}

Academic Clinical Fellow, Centre for Primary Care and Health Services Research, University of Manchester, Manchester

\section{Kath Checkland}

Professor of Health Policy and Primary Care, Centre for Primary Care and Health Services Research, University of Manchester, Manchester.

\section{Luke Munford,}

Senior Lecturer in Health Economics, Centre for Primary Care and Health Services Research, University of Manchester, Manchester.

\section{REFERENCES}

1. Office for National Statistics. Prevalence of ongoing symptoms following coronavirus (COVID-19) infection in the UK. 2021

2. Lopez-Leon S, Wegman-Ostrosky T, Perelman $C$, et al. More than 50 long-term effects of COVID-19: a systematic review and meta analysis. Sci Rep 2021; 11(1): 16144

3. GOV.UK. Coronavirus (COVID-19) in the UK UK summary. 2021. https://coronavirus.data. gov.uk laccessed 1 Dec 2021).

4. Office for National Statistics. Technical article: updated estimates of the prevalence of post-acute symptoms among people with coronavirus (COVID-19) in the UK, 26 April 2020 to 1 August 2021. 2021.

5. Public Health England. Disparities in the risk and outcomes of COVID-19. London: PHE, 2020. https://assets.publishing.service.gov. uk/government/uploads/system/uploads/ attachment_data/file/908434/Disparities in the risk and outcomes of COVID August_2020_update.pdf (accessed 3 Dec 2021)

6. Watt $\mathrm{G}$. The inverse care law revisited: a continuing blot on the record of the National Health Service. Br J Gen Pract 2018; DOI: https://doi.org/10.3399/bjgp18X699893.

\section{ADDRESS FOR CORRESPONDENCE}

\section{Joseph Hutchinson}

Centre for Primary Care and Health Services

Research, University of Manchester, Williamson

Building, Manchester M13 9PL, UK.

Email: joseph.hutchinson2anhs.net

\section{Sam Khavandi,}

Research Associate, Centre for Primary Care and Health Services Research, University of Manchester, Manchester

\section{Matthew Sutton,}

Professor of Health Economics, Centre for Primary Care and Health Services Research, University of Manchester, Manchester.

\section{Funding}

Kath Checkland and Matthew Sutton receive research funding from the Policy Research Unit in Health and Social Care Systems and Commissioning (PRUComm). PRUComm is funded by the National Institute for Health Research (NIHR) Policy Research Programme (Ref: PR-PRU-1217-20801). Sam Khavandi is fully funded, and Matthew Sutton and Luke Munford are part-funded, by the NIHR Applied Research Collaboration Greater Manchester (Ref: NIHR200174). The views expressed are those of the authors and not necessarily those of the Policy Research Programme, NIHR, or the Department of Health and Social Care.

\section{Provenance}

Freely submitted; externally peer reviewed

\section{Competing interests}

The authors have declared no competing interests.

DOI: https://doi.org/10.3399/bjgp22X718505

7. Gershlick B, Fisher R. A worrying cycle of pressure for GPs in deprived areas. Health Foundation, 2019. https://www.health.org.uk/ news-and-comment/blogs/a-worrying-cycle-ofpressure-for-gps-in-deprived-areas laccessed 1 Dec 2021).

8. NHS England. Enhanced service specification - long COVID 2021/22. 2021. https://wmw. england.nhs.uk/wp-content/uploads/2021/06/ C1313-ess-long-covid-21-22.pdf laccessed 1 Dec 2021).

9. Munford L. Khavandi S. Bambra C, et al. A year of COVID-19 in the North: Regional Inequalities in health and economic outcomes. Newcastle: Northern Health Science Alliance, 2021.

10. Gathergood J, Guzingher F, Guttman-Kenney B, et al. Levelling down and the COVID-19 lockdowns: uneven regional recovery in UK consumer spending. Covid Economics 2021; 67: 24-52.

11. Office for National Statistics. Coronavirus and vaccine hesitancy, Great Britain: 28 April to 23 May 2021. 2021

12. Jia $L$, Meng $Q$, Scott $A$, et al. Payment methods for healthcare providers working in outpatient healthcare settings. Cochrane Database Syst Rev2021; 1(1): CD011865. 